\title{
Study of Antibacterial Efficacy of Hybrid Chitosan-Silver Nanoparticles for Prevention of Specific Biofilm and Water Purification
}

\author{
Somnath Ghosh, ${ }^{1}$ Tasneem Kausar Ranebennur, ${ }^{2}$ and H. N. Vasan ${ }^{1}$ \\ ${ }^{1}$ Solid State and Structural Chemistry Unit, Indian Institute of Science, Bangalore 560 012, India \\ ${ }^{2}$ Department of Molecular Reproduction, Development and Genetics, Indian Institute of Science, Bangalore 560 012, India
}

Correspondence should be addressed to H. N. Vasan, vasan@sscu.iisc.ernet.in

Received 9 December 2011; Accepted 22 December 2011

Academic Editor: Yuriy A. Knirel

Copyright (C) 2011 Somnath Ghosh et al. This is an open access article distributed under the Creative Commons Attribution License, which permits unrestricted use, distribution, and reproduction in any medium, provided the original work is properly cited.

\begin{abstract}
Antibacterial efficacy of silver nanoparticles (Ag NPs) deposited alternatively layer by layer (LBL) on chitosan polymer in the form of a thin film over a quartz plate and stainless steel strip has been studied. An eight-bilayer chitosan/silver (Cs/Ag) ${ }_{8}$ hybrid was prepared having a known concentration of silver. Techniques such as UV-visible spectroscopy, inductively coupled plasma optical emission spectroscopy (ICP-OES), and atomic force microscopy (AFM) were carried out to understand and elucidate the physical nature of the film. Gram-negative bacteria, Escherichia coli (E. coli), were used as a test sample in saline solution for antibacterial studies. The growth inhibition at different intervals of contact time and, more importantly, the antibacterial properties of the hybrid film on repeated cycling in saline solution have been demonstrated. AFM studies are carried out for the first time on the microbe to know the morphological changes affected by the hybrid film. The hybrid films on aging (3 months) are found to be as bioactive as before. Cytotoxicity experiments indicated good biocompatibility. The hybrid can be a promising bioactive material for the prevention of biofilms specific to E. coli and in purification of water for safe drinking.
\end{abstract}

\section{Introduction}

In present day clinical applications, implantable medical devices are extensively used as supporting materials for heart valves, catheters, artificial organs, and so on [1-4]. But many of these engrafted devices were found to end up with microbial colonies at the surface and in the formation of biofilms causing foreign-body infection $[5,6]$. Such biofilm related infections are a major cause for morbidity and mortality $[7,8]$. They also show extraordinary resistance to conventional antibiotics and biocides [9-11]. About sixty percent of the estimated bacterial infections in hospitals can be attributed to bacterial biofilms [2, 7]. Among the gramnegative bacteria, E. coli which causes broad spectrum of diseases affecting large population has been an important model organism for in vitro analysis of biofilm formation and associated infection [12-16].
One of the ways to prevent the formation of biofilm on the implanted medical devices causing infection is by surface coating of suitable biocompatible material, which can function as resistant to the growth of microbial colonies. Various materials have been employed for such coatings, for example, antimicrobial polymers [17, 18], antimicrobial nanoparticles-polymer composites $[19,20]$, and grafting the surface with antiadhesive polymers [21, 22]. Among the various metals, silver and silver ions for a long time were known to have strong inhibitory and bactericidal effect as well as a broad spectrum of antimicrobial activity [23-29] and are also found to be wound-healing agents with less toxicity $[30,31]$. When the metal particles are in nanosize, it further enhances many of these properties, because of the increase in surface area caused by increase in surface-tovolume ratio [32]. Thus, when the silver nanoparticles are coated on the implanted devices by some means, in addition 
to the prevention of biofilm formation, they may also have an advantage of healing wounds around them [33]. In comparison to many antibiotics, development of resistance against Ag NPs by bacteria is scarcely known [34, 35]. Hence, Ag NPs in a suitable matrix as a coat may be useful to prevent the formation of biofilm [36] and also as antibacterial agent for the purification of water for safe drinking [37].

Layer-by-layer (LBL) coating of suitable material in the form of film on devices is one of the easy techniques, which may be employed for this purpose $[38,39]$. LBL assembly has drawn many researchers' attention for surface coating in the recent past, because it is relatively simple, with minimal requirement of chemicals and inexpensive equipment [40, 41]. The principle behind the LBL method is the sequential deposition of organic/inorganic materials through electrostatic interaction between polycation and anion which makes bilayers $[42,43]$. The obtained film thickness is usually in the nanometre scale range [44] and homogeneity can be controlled precisely by manipulating few film deposition parameters such as solution $\mathrm{pH}$, ionic strength, and immersion time [45-47].

Among the naturally occurring polymers, chitosan may be a good candidate for coating by the LBL technique, because it is a biodegradable polysaccharide and also a polycation, which helps for the electrostatic interaction with the opposite charge. Earlier people have reported the antibacterial studies of chitosan/Ag hybrid systems in the form of powder and film [48-54], and most of these studies are carried out in nutrient broth, and repeated use of such materials are not reported. However, few have reported on the repeated antibacterial activity of $\mathrm{Ag}$ containing hybrid systems. For example, Wei et al. [54] have prepared by dipping glass slides into solution containing silver nitrate and chitosan for $18 \mathrm{~h}$ at $60^{\circ} \mathrm{C}$ and have tested the antibacterial activity by recycling for several days in nutrient broth. Sambhy et al. [55]. have prepared silver bromide embedded in cationic polymer, poly(4-vinyl-n-hexylpyridinium bromide) and have studied the antimicrobial activity in LB broth over extended periods. But none of these studies have reported the cytotoxicity of the materials fabricated.

Here, we report layer-by-layer (LBL) dip coating method for the preparation of chitosan/silver NPs hybrid thin films on quartz plate, which is simpler and faster, compared to the earlier reported silver/polymer hybrids $[54,55]$. The films are well characterized by various techniques such as UV-visible spectroscopy, inductively coupled plasma optical emission spectroscopy (ICP-OES) and atomic force microscopy (AFM) studies. The antibacterial efficacy of the film against pathogenic Escherichia coli (MTCC 1302) is being studied at different intervals of contact time and also the antibacterial properties of the film on repeated cycling in saline solution have been demonstrated. The microbe E. coli is relevant for both the prevention of biofilm formation and in the purification of water for safe drinking [12, 56, 57]. Also, saline solution represents nearest to natural aquatic system, particularly in the application of purification of water [58]. AFM studies are also carried out on the bacteria before and after treatment to understand the morphological changes, which might have occurred due to the death of bacteria.
Moreover, for the first time just $\mathrm{Ag}^{+}$ions are incorporated into chitosan by LBL technique and its antibacterial activity compared with the $(\mathrm{Cs} / \mathrm{Ag})_{8}$ hybrid.

Similar coatings are also carried out on stainless steel strips and its antibacterial property is reported for just coated and for three months aged samples to evaluate the stability and antibacterial efficacy on aging. The antibacterial property of the hybrid is found to be the same on aging with good adhesion on the stainless steel strip, demonstrating the stability of the film. The hybrid can be a promising bioactive material for the prevention of biofilms specific to $E$. coli and in general against gram-negative bacteria and also for purification of water for safe drinking.

\section{Methods}

2.1. Materials. $\mathrm{AgNO}_{3}$ (99.9\%, S.D Fine-Chem Ltd., India), $\mathrm{NaCl}$ (99.9\%, Qualigens, India), sodium citrate dehydrate (99.0\%, Ranbaxy, India), sodium borohydride (98\%, S.D Fine-Chem Ltd., India), chitosan $\left(M_{w} \sim 200,0000\right.$, Aldrich), $\mathrm{H}_{2} \mathrm{O}_{2}$ (Ranbaxy, India), $\mathrm{H}_{2} \mathrm{SO}_{4}$ (Nice Chem Pvt, Ltd., and India), nutrient broth (Hi-Media Laboratories Ltd, India) were used as such without any further purification. A standard reference strain, Escherichia coli MTCC 1302, was supplied by M.S. Ramaiah Hospital, Bangalore, India. Ultrapure water (Millipore) with specific resistance of $18.2 \mathrm{M} \Omega \mathrm{cm}$ was used throughout the experiment.

2.2. Stock Solution. The following stock solutions were prepared and preserved to carry out the experiments repeatedly. Known weight of chitosan was dissolved in millipore water at pH 4.00 (adjusted by $1 \%$ acetic acid) to have a concentration of $1 \mathrm{mg} / \mathrm{mL}$. A saline solution was prepared by dissolving $4.5 \mathrm{~g}$ of $\mathrm{NaCl}$ in $500 \mathrm{~mL}$ of millipore water and sterilized. Silver nitrate and sodium citrate of $1 \mathrm{mM}$ concentration were also prepared in millipore water.

2.3. Synthesis of Silver NPs. Silver NPs were synthesized according to the reported procedure [59]. Briefly, $0.6 \mathrm{~mL}$ of freshly prepared ice-cooled sodium borohydride solution $(40 \mathrm{mM})$ was added to $20 \mathrm{~mL}$ of $1 \mathrm{mM}$ silver nitrate and sodium citrate on stirring for few minutes. The immediate appearance of luminescent yellow color indicated the formation of silver NPs caped with citrate.

2.4. Preparation of $(\mathrm{Cs} / \mathrm{Ag})_{8}$ Hybrid Film. Before the thin film preparation of chitosan, quartz slides $(2.5 \mathrm{~cm} \times 2.5 \mathrm{~cm})$ were thoroughly cleaned in piranha solution $(7: 3 \mathrm{v} / \mathrm{v}$ $\mathrm{H}_{2} \mathrm{SO}_{4} / \mathrm{H}_{2} \mathrm{O}_{2}$ ) and then rinsed several times with millipore water. Then each slide was dipped in chitosan solution $(1 \mathrm{mg} / \mathrm{mL})$ for $2 \mathrm{~h}$ and then rinsed with millipore water carefully to remove any unadsorbed chitosan and dried under nitrogen gas flow. Further it was placed in citrate capped Ag NPs solution and allowed to adsorb Ag NPs for $2 \mathrm{~h}$, followed by three washings in millipore water before depositing the next layer of chitosan. This process was repeated for several times to get multilayer films of known 


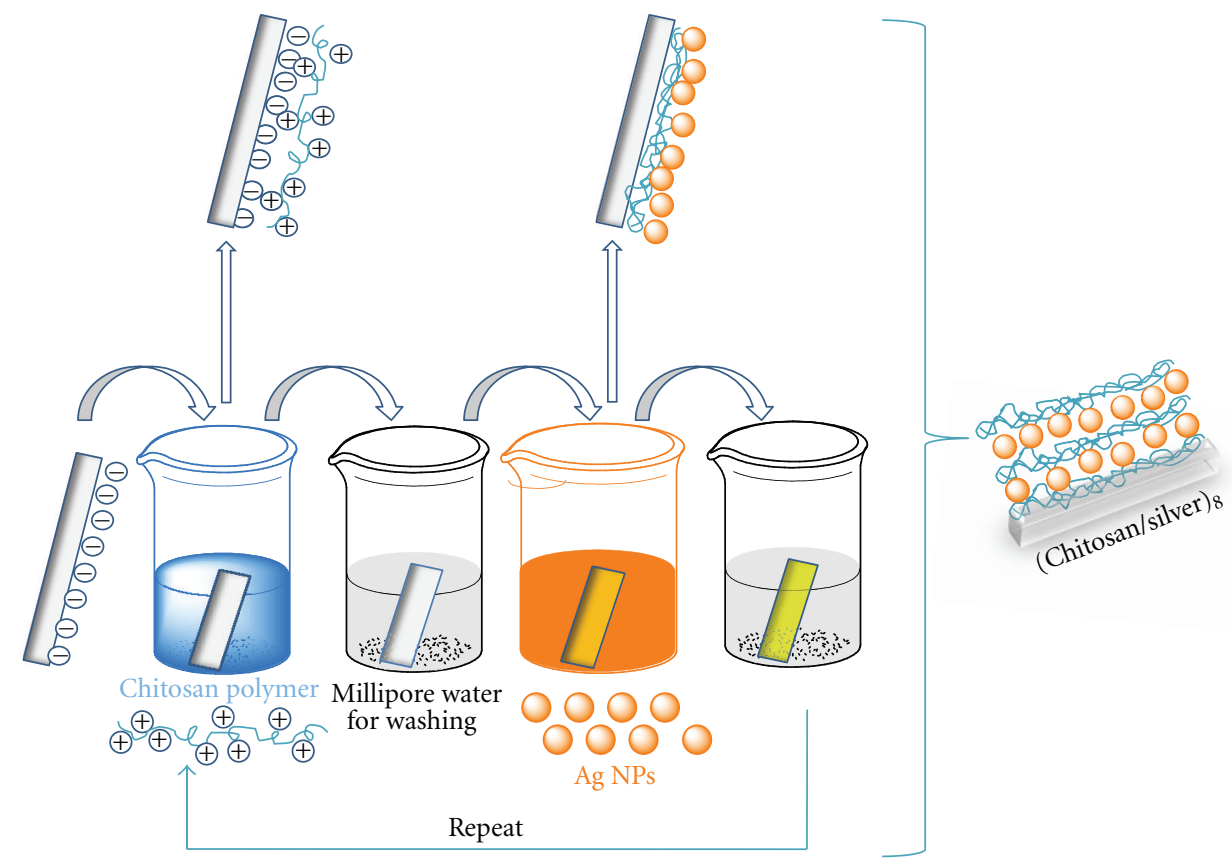

FIGURE 1: Schematic illustration of LBL assembled thin film preparation through electrostatic interaction.

bilayers as shown in Figure 1. At every step the film was monitored by UV-visible spectroscopy. Similarly an eight bilayer $\left(\mathrm{Cs} / \mathrm{Ag}^{+}\right)_{8}$, containing $\mathrm{Ag}^{+}$citrate capped, was fabricated on a quartz slide of the same dimension by taking the same concentrations of original $\mathrm{AgNO}_{3}$ and sodium citrate. Also a similar coating was done on a stainless steel strip $(0.5 \mathrm{~cm} \times$ $1.0 \mathrm{~cm}$ ) (grade 304) as described above by prior cleaning of the strip according to Claire-Marie Pradier procedure [60], briefly, the steel strips were first polished with $\mathrm{SiC}$ paper and alumina paste until a mirror finish was obtained. After being polished, the strips were successively ultrasonicated for $5 \mathrm{~min}$ in acetone, $5 \mathrm{~min}$ in millipore water, $15 \mathrm{~min}$ in hexane, and further $15 \mathrm{~min}$ in millipore water at $50^{\circ} \mathrm{C}$ and then dipped in warm acetone $\left(50^{\circ} \mathrm{C}\right)$ for another $15 \mathrm{~min}$. Strips were then etched by sulfochromic acid at $60^{\circ} \mathrm{C}$ for $10 \mathrm{~min}$ and extensively washed with milliQ water and dried in $\mathrm{N}_{2}$ flow.

2.5. Instrumentation and Characterization. The UV-visible spectra of each deposition of layers were monitored by a Perkin-Elmer (Lambda 35) spectrometer. The spectrum of a cleaned quartz plate of the same dimension in air was taken for background correction. The total loading of silver in chitosan multilayer was determined by ICP emission spectroscopy using Perkin-Elmer optima 2100 inductively coupled plasma-optical emission (ICP-OES) spectrometer at $\lambda_{328}$ by initially dissolving a known area of the film in $100 \mu \mathrm{L}$ dilute nitric acid $(\sim 3.5 \mathrm{M})$ and thereafter suitable dilutions were made with millipore water. AFM images were taken on the samples in Digital Nanoscope IVA AFM, Veeco Instruments, US, by contact mode in air. Special precautions were taken to prevent the instrument from vibrations. Citrate capped Ag NPs in water were thoroughly sonicated and TEM images were taken in TECNAI F 30 electron microscope. The size of the Ag particle was estimated by digital micrograph software.

To have an estimate of $\mathrm{Ag}^{+}$in $\left(\mathrm{Cs} / \mathrm{Ag}^{+}\right)_{8}$, the $\mathrm{Ag}^{+}$was completely reduced by dipping the slide in sodium borohydride solution, it was dried and UV-visible spectra was obtained and compared with that of $(\mathrm{Cs} / \mathrm{Ag})_{8}$.

For AFM studies of bacterial samples, two coated $(\mathrm{Cs} / \mathrm{Ag})_{8}$ quartz plates were put into the bacterial solution and one was taken out immediately, referred to as zero hour and another plate after $24 \mathrm{~h}$. The bacterial solution was first centrifuged, washed with millipore water, and from the resulting bacterial mass a small amount was spread over mica foil and dried for final AFM investigations.

2.6. Bacterial Inhibition. Cell viability was assessed by counting colony-forming unit (CFU) according to the following procedure. E. coli was cultured in a nutrient broth solution at $37^{\circ} \mathrm{C}$ overnight in a mechanical shaker. $100 \mu \mathrm{L}$ of this fresh bacterial culture was poured into two sterilized beakers each containing $10 \mathrm{~mL}$ of saline solution and incubated at $37^{\circ} \mathrm{C}$ with gentle mechanical shaking. To one of them only sterilized quartz plate (positive control), and to the other $(\mathrm{Cs} / \mathrm{Ag})_{8}$ deposited quartz plate (test beaker), was kept. At an interval of one hour, $100 \mu \mathrm{L}$ of the incubated solution was taken and diluted consecutively two times with $9.9 \mathrm{~mL}$ of sterile saline solution and from that $100 \mu \mathrm{L}$ solution was taken for plating in nutrient agar plates. After overnight incubation at $37^{\circ} \mathrm{C}$, the viable colonies were visible to the naked eye and thus were counted manually and compared with positive control. Optical density at $600 \mathrm{~nm}$ was read by UV-visible spectrometer at different intervals of the test samples, that is, $0 \mathrm{~h}, 4 \mathrm{~h}$, and $24 \mathrm{~h}$, to determine the bacterial growth. 
Antibacterial test for freshly prepared stainless steel coated with chitosan-silver of eight bilayers and for sample preserved for three months, was done by the zone of inhibition method. In brief bacterial lawn was prepared on sterile Muller Hinton agar plates by using a sterile cotton swab. Two strips of stainless steel $(0.5 \mathrm{~cm} \times 1.0 \mathrm{~cm})$, one coated with eight bilayers of chitosan-Ag and another without coating (positive control) were placed at the centre of two separate lawns carefully without touching the other parts and incubated at $37^{\circ} \mathrm{C}$ for $24 \mathrm{~h}$, and the zone around the film was measured on the subsequent day using a centimetre scale.

2.7. In Vitro Cytotoxicity Assay. For the in vitro cytotoxicity assay, the protocol described by Freshney was adapted [61]. It is based on the properties of living cells and dead cells. The live cells possess intact cell membrane that excludes certain dyes, such as trypan blue, eosin, or propidium, whereas dead cells do not. Trypan blue dye exclusion assay was used here to determine the number of viable cells. Simply the cell suspensions are mixed with trypan blue dye and are visually examined to determine whether they have taken up or excluded the dye. In the protocol presented here, a viable cell will have a clear cytoplasm whereas a nonviable cell will have a blue cytoplasm. Briefly, $1.0 \times 10^{5}$ HEK 293 fully grown cells were washed with Dulbecco's phosphate buffered saline (DPBS) and harvested using $0.5 \mathrm{~mL}$ of $1 \mathrm{x}$ trypsin-EDTA. Then, after resuspending in fresh culture medium containing $10 \%$ fetal bovine serum (FBS), $0.5 \mathrm{~mL}$ of the suspension was seeded into culture wells. Further, the quartz plates coated $(\mathrm{Cs} / \mathrm{Ag})_{8}$ were sterilized with UV irradiation for 15 minutes to avoid contamination and then washed three times with sterile PBS and then dipped into the wells having fully grown cells and incubated at $5 \% \mathrm{CO}_{2}$ and $37^{\circ} \mathrm{C}$ for $48 \mathrm{~h}$. Similarly, sterile blank quartz plates were used as controls. After $48 \mathrm{~h}$ of incubation, the plates were washed with PBS, and $0.4 \%$ trypan blue dye solution was added and allowed to stand for 1-2 min. The total number of cells as well as the number of blue cells were counted using a Neubauer hemocytometer.

\section{Results}

3.1. Preparation of $(\mathrm{Cs} / \mathrm{Ag})_{8}$ Hybrid Film. In the procedure described earlier, incorporation of negatively charged citrate capped Ag NPs between two layers of positively charged chitosan films through electrostatic interaction is schematically shown (Figure 1), which provides a platform to grow LBL chitosan/silver hybrid thin films.

Figure 2 shows the UV-visible absorption of Cs/Ag thin film coated on quartz plate after each bilayer of chitosan and Ag. The intensity of plasmon band of Ag NPs increases with the number of bilayers of Cs/Ag and is found to be linear (inset Figure 2), indicating the linear increase in $\mathrm{Ag}$ NPs concentration as the number of bilayers increased. We have restricted the $\mathrm{Cs} / \mathrm{Ag}$ to eight bilayers, taking into consideration an optimum concentration of silver nanoparticles in the hybrid. From ICP analysis, the total silver concentration in $(\mathrm{Cs} / \mathrm{Ag})_{8}$ is found to be around $18.9 \pm 4.7 \mu \mathrm{g} \mathrm{cm}^{-2}$ and $26 \pm$ $3.0 \mu \mathrm{g} \mathrm{cm}^{-2}$ for film on quartz and stainless steel, respectively.

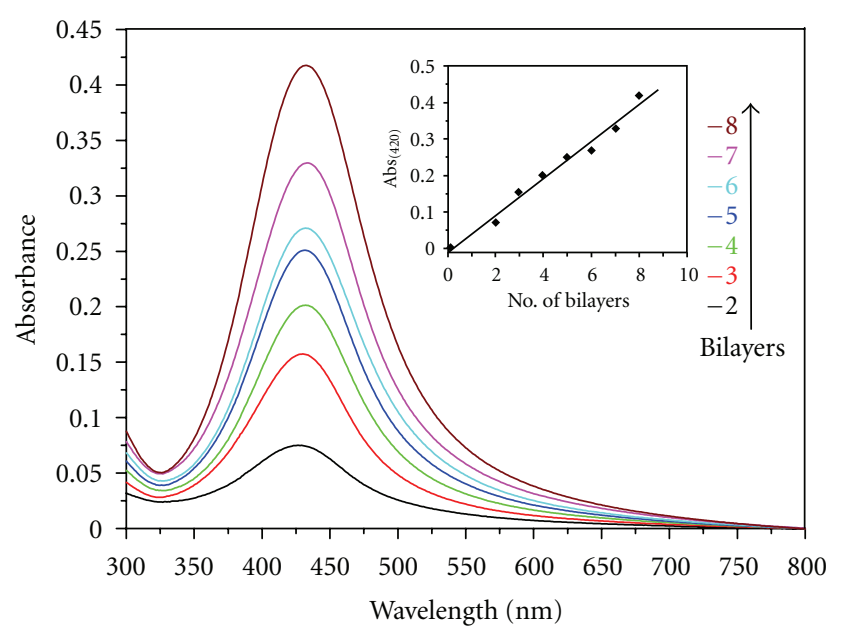

FIGURE 2: UV-visible spectra of each bilayers of (Cs/Ag). Inset showing the absorption versus number of bilayers of $(\mathrm{Cs} / \mathrm{Ag})$.

On comparing the obtained intensities of UV-visible spectra of $(\mathrm{Cs} / \mathrm{Ag})_{8}$ and $\left(\mathrm{Cs} / \mathrm{Ag}^{+}\right)_{8}$, it is found that the concentration of Ag in both the hybrids are more or less the same (see (S1) in Supplementary Material available online at doi:/10.1155/2011/93759).

3.2. AFM Studies. The topographical changes in two pairs of successive layers 2nd and 3rd, 14th and 15th (all even layers are Ag and all odd layers are chitosan) as seen by AFM are shown in Figures 3(a), 3(b), 3(c), and 3(d), respectively. It reveals that surface texture looks more uniform when outermost layer (3rd and 15th) is chitosan (Figures 3(b) and 3(d)), when compared to the layer ending with Ag NPs (Figures 3(a) and 3(c)). The AFM cross-sectional analysis shown in Figure 3(e) taken along the line indicated in Figure 3(c) shows an average size of spherical Ag NPs. In case of chitosan layer (15th layer) the embedded silver nanoparticles are not clearly visible (Figure 3(c)) because of masking of chitosan. Also Figure 3(f) shows a TEM picture of synthesized Ag NPs and the size of the particles is found to be approximately $50 \mathrm{~nm}$.

\subsection{Bactericidal Properties of $(\mathrm{Cs} / \mathrm{Ag})_{8}$ and $\left(\mathrm{Cs} / \mathrm{Ag}^{+}\right)_{8} \mathrm{Hybrid}$} Film. To establish the bactericidal properties of $(\mathrm{Cs} / \mathrm{Ag})_{8}$ hybrid on quartz plate, the experiments were carried out in saline solution under biological pH 7.4. Table 1 shows the $\mathrm{OD}_{600}$ of the bacterial solution at various contact times. From the optical density values one can infer that the growth of bacteria is almost negligible at the end of 4 hours, and it is further tapered after $24 \mathrm{~h}$ when compared to the control.

This is further compared with the percentage survival of bacteria with time and is calculated using the relation ( (No. of colonies in test sample/No. of colonies in control plate $\times 100$ ) by CFU counting and is shown in Figure 4(c). There is a steep decrease in percentage of survival up to one hour and slowly tapers down to almost zero at the end of four hours. This is further clearly seen in the agar plate photographs taken after four hours (Figure 4, inset). The 


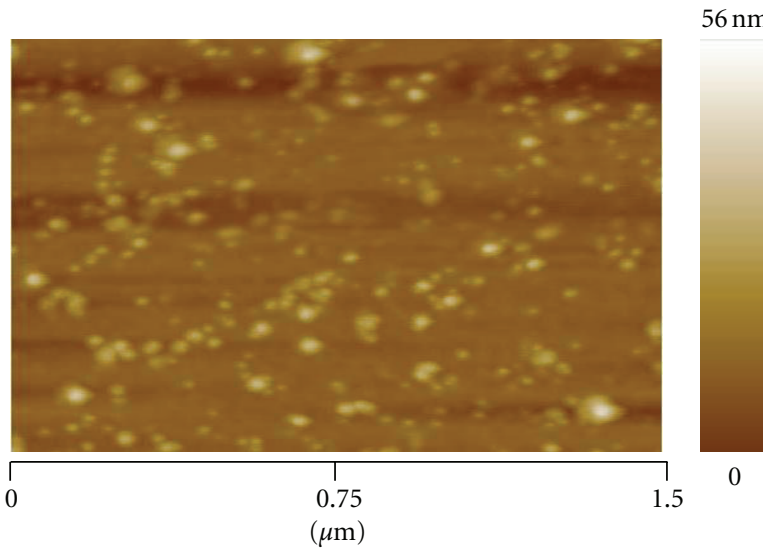

(a)

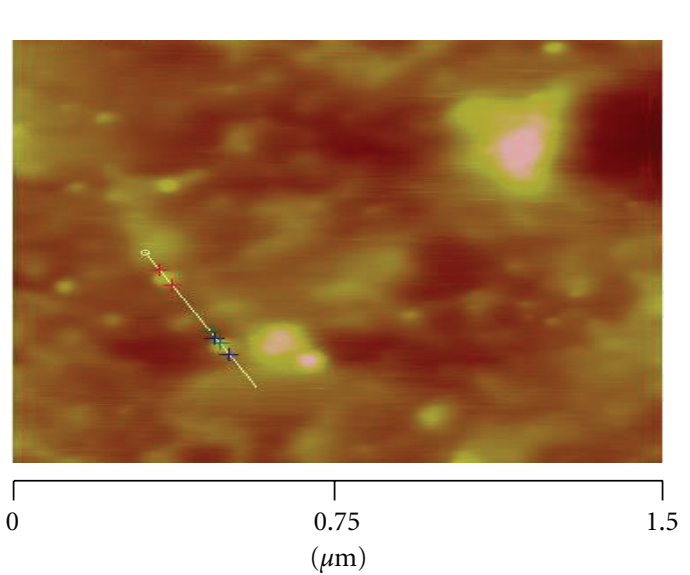

(c)

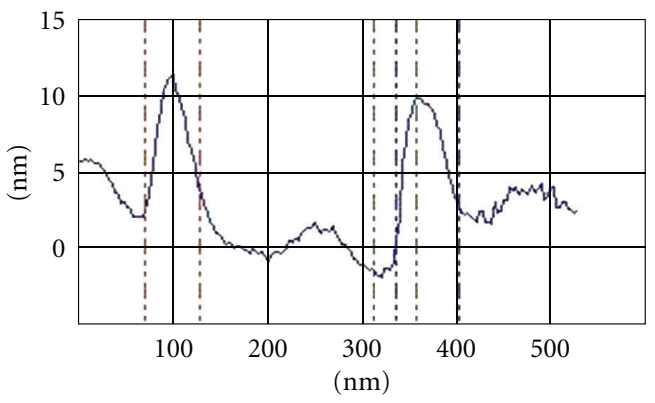

(e)

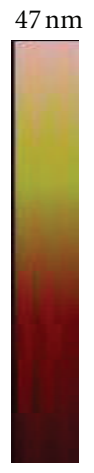

\section{0}

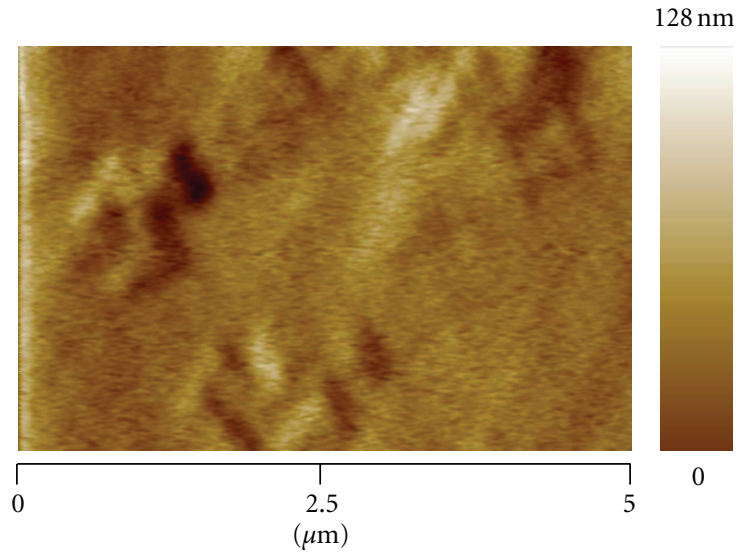

(b)

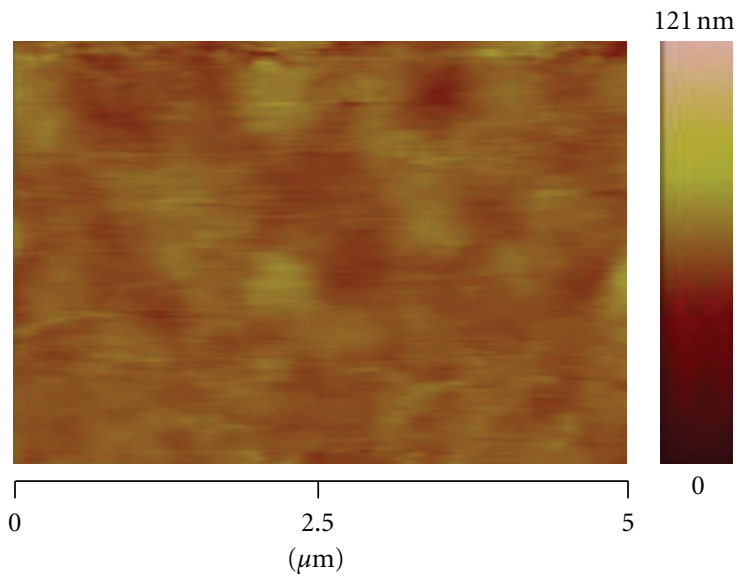

(d)

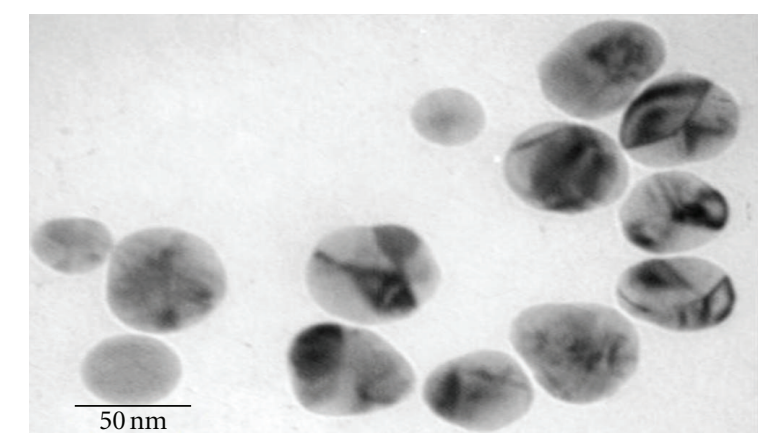

(f)

Figure 3: AFM picture showing (a) 2nd layer with silver, (b) 3rd layer with Chitosan, (c) 14th layer with silver, (d) 15th layer with uppermost Chitosan, (e) cross sectional analysis of the particles indicated by the straight line in figure (c), and (f) TEM picture of the synthesized AgNPs.

percentage of survival of the bacteria on $\left(\mathrm{Cs} / \mathrm{Ag}^{+}\right)_{8}$ hybrid and also on the test sample containing only chitosan/citrate, which is also eight bilayers prepared in a similar method is also shown in Figure 4. In the first one hour, the percentage survival on $\left(\mathrm{Cs} / \mathrm{Ag}^{+}\right)_{8}$ hybrid is almost the same as $(\mathrm{Cs} / \mathrm{Ag})_{8}$ hybrid, and remains with this survival even after four hours (Figure 4(b)). Whereas in the case of test sample, there is no significant change in percentage survival $(100 \%)$ of bacteria throughout the contact time observed (Figure 4(a)). The eight bilayers of the test sample are monitored by IR spectra (see S2) during deposition. The intensity increase of the spectra is seen with the progress of the bilayers.

The bacterial morphology changes were studied by AFM before treatment (0 hour) (Figure 5(a)) and after $24 \mathrm{hr}$ treatment (Figure $5(\mathrm{~d})$ ) with $(\mathrm{CS} / \mathrm{Ag})_{8}$ hybrid on quartz plate. Figures $5(\mathrm{~b})$ and $5(\mathrm{e})$ are the respective $3 \mathrm{D}$ images. 
TABLE 1: The optical density study on E. coli at $600 \mathrm{~nm}$ at various contact times of $(\mathrm{Cs} / \mathrm{Ag})_{8}$ hybrid.

\begin{tabular}{lcc}
\hline Time (h) & Control & OD $_{600}$ \\
& $0.0375 \pm\left(1.868 \times 10^{(-3)}\right)$ & $0.0375 \pm\left(1.798 \times 10^{(-3)}\right)$ \\
\hline 00 & $0.1891 \pm\left(16.70 \times 10^{(-3)}\right)$ & $0.0426 \pm\left(3.074 \times 10^{(-3)}\right)$ \\
04 & $0.2219 \pm\left(12.04 \times 10^{(-3)}\right)$ & $0.0778 \pm\left(14.59 \times 10^{(-3)}\right)$ \\
24 &
\end{tabular}

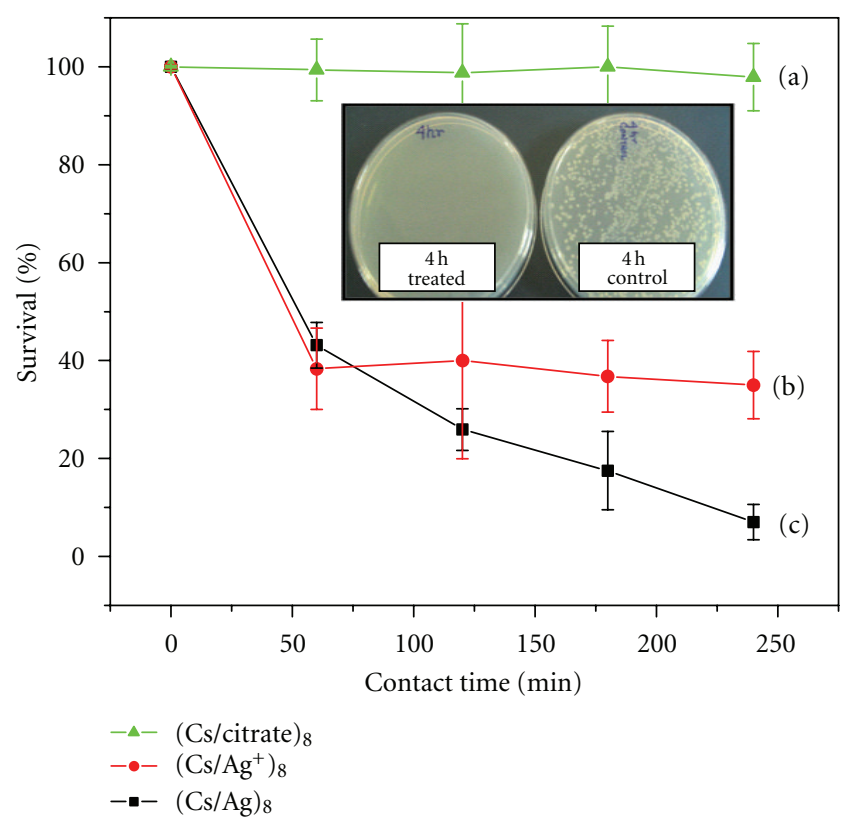

FIgURE 4: Viable cell count test by nutrient agar plating: percentage survival bacteria versus contact time, (a) (Cs/citrate) ${ }_{8}$, (b) $\left(\mathrm{Cs} / \mathrm{Ag}^{+}\right)_{8}$ and $(\mathrm{c})(\mathrm{Cs} / \mathrm{Ag})_{8}$. Inset showing the optical photographs of control agar plates and after $4 \mathrm{~h}$ of contact with $(\mathrm{Cs} / \mathrm{Ag})_{8}$.

TABle 2: rms roughness and cell height of E. coli membrane obtained from AFM.

\begin{tabular}{lcc}
\hline Time $(\mathrm{h})$ & 0 & 24 \\
rms roughness $(\mathrm{nm})$ & $29.57 \pm 4.31$ & $5.17 \pm 3.48$ \\
$\begin{array}{l}\text { Height of the cell }(\mathrm{nm}) \\
\begin{array}{l}\text { No. of } E \text {. coli on which } \\
\text { roughness has been } \\
\text { calculated }\end{array}\end{array}$ & $\sim 354$ & $\sim 103$ \\
\hline
\end{tabular}

Figures 5(c) and 5(f) are phase images of (a) and (d), respectively. The rms roughness of the bacterial membrane and height of the cell are tabulated in Table 2.

3.4. Repetitive Use of Hybrid As an Antibacterial Agent. The retention of the prepared film as an effective antibacterial agent on repeated cycling is desirable in order to have cheap and affordable material for practical applications [62], such as in the purification of water. After each antibacterial test the $(\mathrm{Cs} / \mathrm{Ag})_{8}$ quoted quartz plate was thoroughly washed with sterile water several times and allowed to dry in air and was recycled for another three times in saline solution containing bacteria. Each time the percentage survival of bacteria was determined and also UV-visible spectra of the film were taken after each cycle and the obtained results are shown in Figure 6.

3.5. Zone of Inhibition (ZOI). The zone of inhibition test result is depicted in the Figure 7 for a strip of stainless steel coated $(\mathrm{Cs} / \mathrm{Ag})_{8}$ and for the uncoated (control) against $E$. coli. A zone of $\sim 0.5 \mathrm{~cm}$ diameter around the coated steel (red dashed circle) has been found for both just coated and threemonth preserved sample showing the antibacterial activity of the coated steel and no zone was seen around the uncoated strip of steel (yellow dashed square).

3.6. In Vitro Cytotoxicity Assay. Although (Cs/Ag) $)_{8}$ seems to have good antibacterial activity, its biocompatibility is necessary for any bioapplications [63]. One of the indications of the biocompatibility characteristics of the coated slide is to inhibit the growth of host cells (e.g., mammalian cells such as humans). To evaluate the effect of $(\mathrm{Cs} / \mathrm{Ag})_{8}$ on mammalian cells (HEK 293), quartz slides coated with $(\mathrm{Cs} / \mathrm{Ag})_{8}$ film were exposed to already grown cells and incubated for $48 \mathrm{~h}$, and the protocol was followed as described earlier and were repeated three times.

\section{Discussion}

Our interests in the study of a cheap and effective inorganic/organic hybrid-based antimicrobial agent for safe drinking water have earlier led to the development of Ag/agar-agar films [24]. Here we have chosen chitosan/silver hybrid system, keeping in mind that it would serve the dual function as an antimicrobial agent for purification of water and also as a protective film on medical devices in the prevention of biofilm formation. Chitosan, which is a naturally occurring polysaccharide, is a biocompatible and biodegradable material. It has a large number of amino groups having a $\mathrm{pKa}$ value of $\sim 6.5$, and can easily protonate in acidic or neutral solution, making it water soluble, and it can readily bind to negatively charged surfaces. Chitosan itself can act as antibacterial agent, when present in requisite quantities $[64,65]$. Quartz plate when treated with a piranha solution and steel treated with sulfochromic acid, builds a surface negative charge, which in turn facilitates the binding of the positively charged chitosan. Further, the negatively charged citrate caped Ag NPs binds to chitosan forming a bilayer. The linear increase in intensity of the Ag plasmon band with an increase in bilayers (inset Figure 2) indicates that the amount of $\mathrm{Ag}$ bound to each one of the chitosan layer is uniform. From the ICP results of Ag, one can estimate the Ag concentration in each bilayer, and it is found to be around $2.36 \mu \mathrm{g} \mathrm{cm}^{-2}$. Throughout the deposition from 1 to 8 bilayers, the position of plasmon peak $\sim 425 \mathrm{~nm}$ (Figure 2) remains almost the same, indicating that Ag NPs in the bilayers are more or less spherical in shape, which is also seen in TEM (Figure 3(f)). 


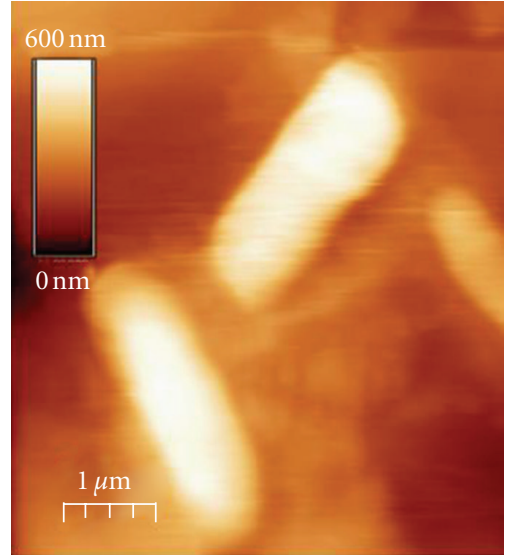

(a)

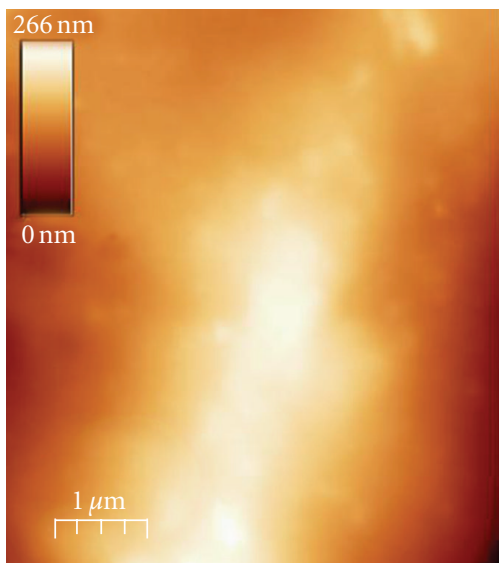

(d)

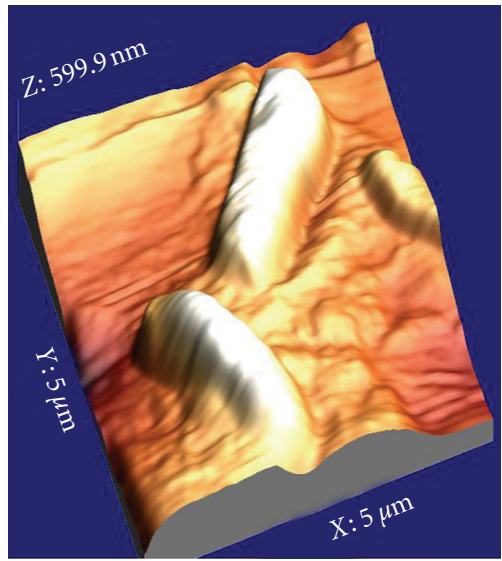

(b)

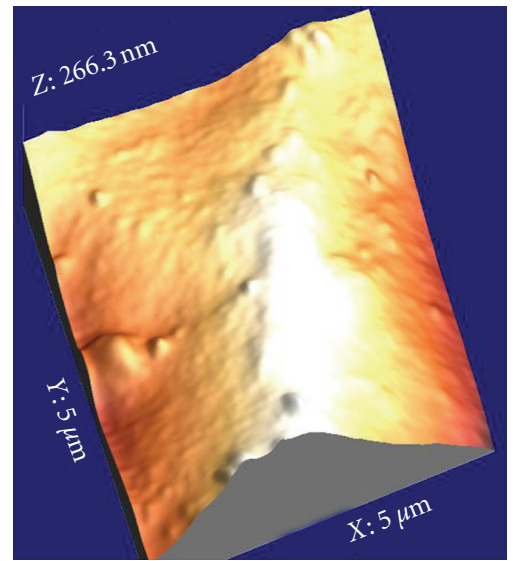

(e)

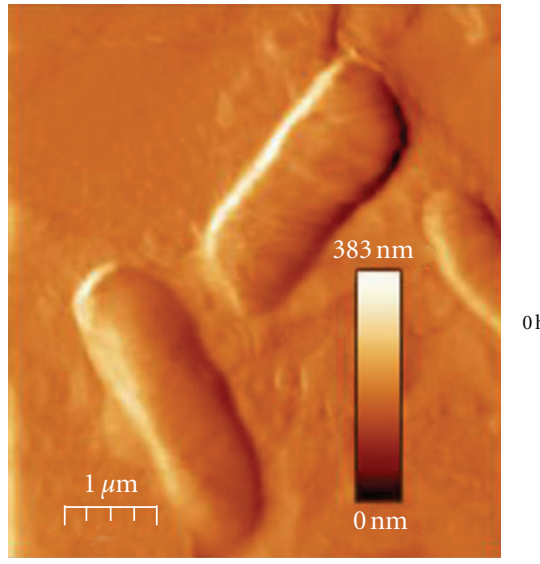

(c)

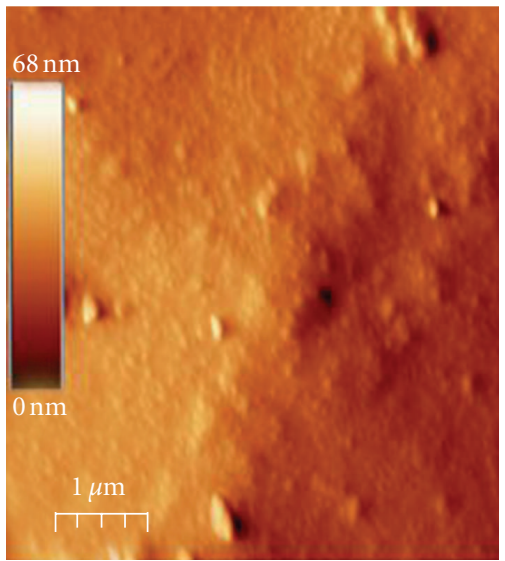

(f)

FIGURE 5: AFM images of bacteria at (a) $0 \mathrm{~h}$ and (d) after $24 \mathrm{~h}$ contact with $(\mathrm{Cs} / \mathrm{Ag})_{8}$ coated quartz plates, (b) and (e) are the respective 3D images, (c) and (f) are phase images of (a) and (d), respectively.

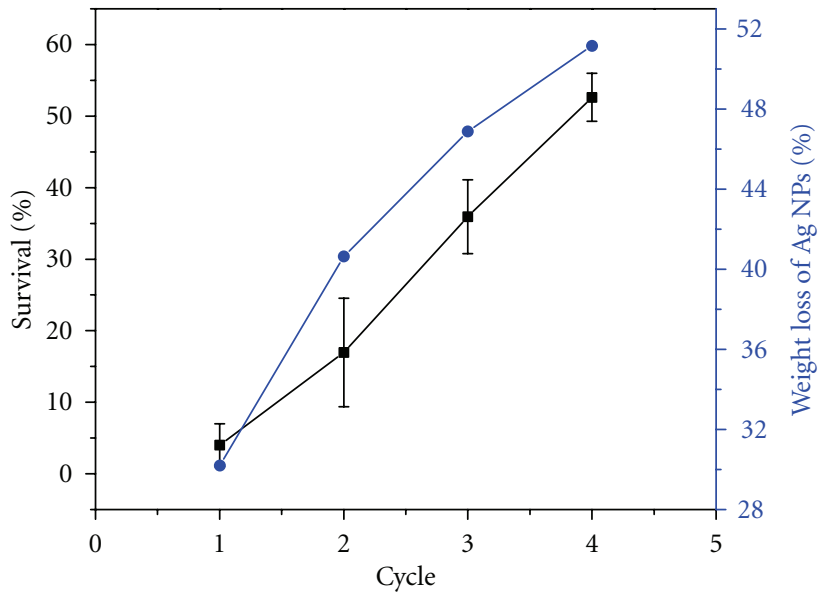

(a)

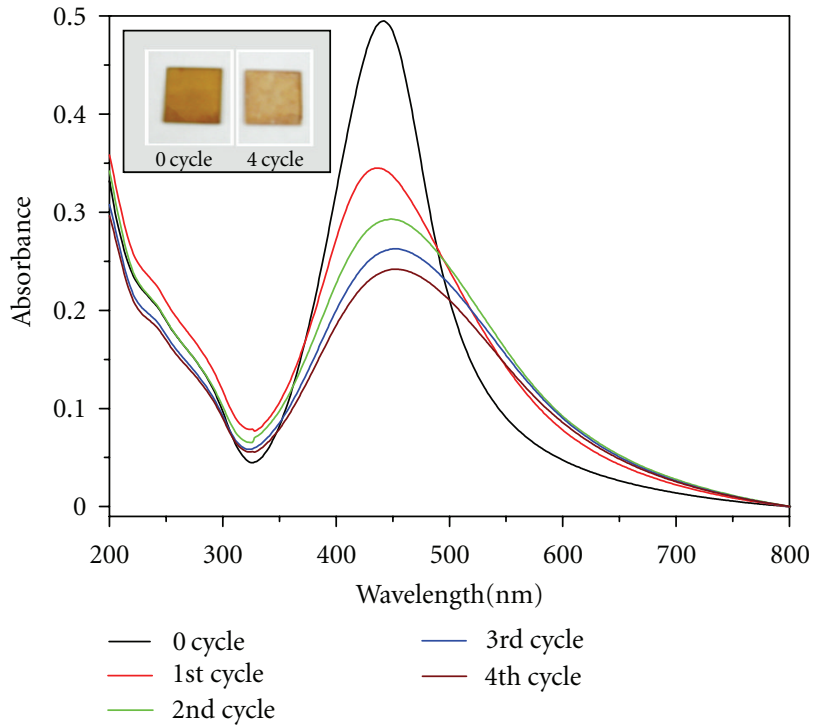

(b)

FIgURE 6: (a) Plot of E. coli surviving bacteria and percentage of weight loss of Ag NPs versus number of cycles. (b) UV-visible absorption peak $(\lambda \sim 420 \mathrm{~nm})$ of $(\mathrm{Cs} / \mathrm{Ag})_{8}$ after each cycle and inset showing the optical photographs of $(\mathrm{Cs} / \mathrm{Ag})_{8}$ coated quartz plate at 0 th cycle and 4 th cycles. 


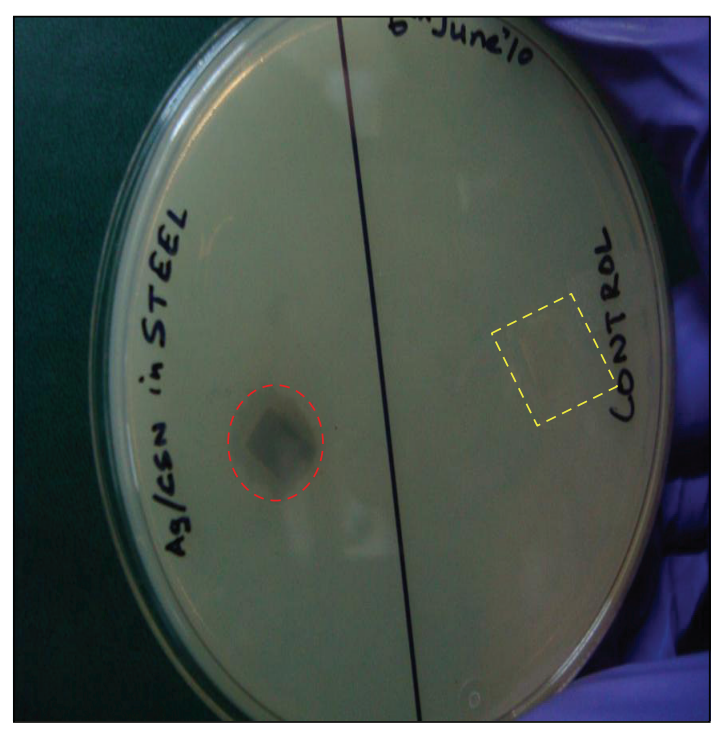

(a)

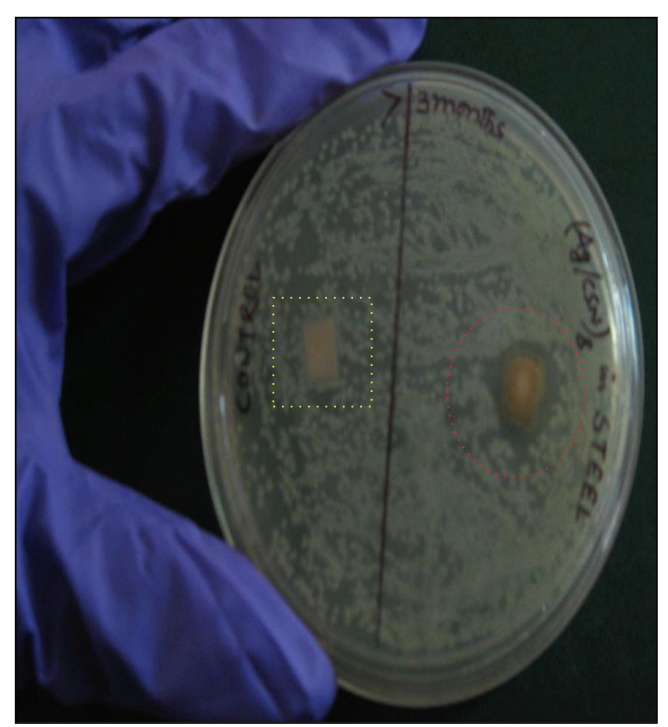

(b)

FIGURE 7: Photograph of zone of inhibition around stainless steel coated with 8 bilayers of chitosan-silver (red dashed line circle) and no zone around uncoated steel (yellow dashed line square): (a) just coated stainless steel and (b) after 3 months of ageing.

Atomic force microscopy (AFM) comes in handy while analyzing the topography of the film on a substrate. While analyzing the data for the hybrid system (Figure 3), it is seen that Ag NPs are well distributed; however, the presence of few islands (bright spots) indicates the agglomeration of Ag NPs. The size of the Ag NPs in solution estimated from the TEM pictures and one between chitosan layers remains almost the same $(\sim 50 \mathrm{~nm})$.

One may be interested to know the activity of the hybrid in contact with said bacteria with time, accordingly the experiments were carried out and the optical density results (Table 1) indicate that at the end of four hours there is no growth of bacteria. This is further confirmed in the percentage survival experiment (Figure 4) and from the corresponding photographs obtained (inset of Figure 4). The percentage survival in both $(\mathrm{Cs} / \mathrm{Ag})_{8}$ and $\left(\mathrm{Cs} / \mathrm{Ag}^{+}\right)_{8}$ hybrids is around $40 \%$ after the initial first hour contact and further reduces to $10 \%$ after four-hour contact in the case of the former, but remains the same in the later.

This may be explained the way the microbes come in contact with the hybrid. As the experiments are bacteriostatic in nature, we presume that the contact is mainly due to the diffusion of silver particles from the hybrid into the solution and physically attacking the microbes. This is further substantiated in the repetitive experiment, which is discussed later. The diffusion of Ag NPs into the saline solution is rather slow compared to $\mathrm{Ag}^{+}$ions, though the initial $\mathrm{Ag}$ concentration is more or less the same in both the samples. This is understandable as the $\mathrm{Cl}^{-}$ions present in saline solution have greater affinity for $\mathrm{Ag}^{+}$compared to $\mathrm{Ag}^{\circ}$. After the first one-hour contact most of the $\mathrm{Ag}^{+}$ present in $\left(\mathrm{Cs} / \mathrm{Ag}^{+}\right)_{8}$ has diffused into the solution and made it ineffective on further contact. And even though it is known that chitosan can be an antibacterial agent and whereas the test hybrid (Cs/citrate $)_{8}$ donot show any antibacterial activity, it may be concluded that the concentration of chitosan present in the hybrid may be very low and there is no synergic antibacterial activity in the case of $(\mathrm{Cs} / \mathrm{Ag})_{8}$ hybrid. One can attribute it only due to the Ag nanoparticles present in the hybrid and it works as a better candidate than $\left(\mathrm{Cs} / \mathrm{Ag}^{+}\right)_{8}$. Further the possibility of Ag NPs ionizing to $\mathrm{Ag}^{+}$ and then attacking the bacteria may be ruled out.

Careful study of the AFM (Figure 5) images obtained on the live and the dead bacteria clearly shows a defined morphology of the live bacteria (Figures $5(\mathrm{a})-5(\mathrm{c})$ ), which is totally absent in the dead ones (Figures $5(\mathrm{~d})-5(\mathrm{f})$ ), indicating the complete destruction of the outer membrane of the bacteria, due to the physical contact of Ag NPs and the bacteria. Similar observations were made by others and have accounted this for the disruption of the cytoplasmic membrane of the bacteria [66-69]. The rms roughness of the bacterial membrane and the height of the cell have also decreased with treatment (Table 2). These phenomena may be attributed to the damage of lipopolysaccharide (LPS) which serves as a permeability barrier and is believed to contribute to the structural rigidity of the cell envelope [6972].

Not many investigations are found in the literature about the recyclability of coated films for antibacterial activity in saline solution. However, when such experiments are carried out, one can evaluate the efficiency of such films for repetitive use. We have investigated this for $(\mathrm{Cs} / \mathrm{Ag})_{8}$ hybrid samples and the results show that after the fourth cycle the bacterial survival was nearly 50\% (Figure 6(a)). This increase in survival may be due to depletion of Ag NPs in the film after each cycle. This is evident from the intensity decrease and increase in full width at half maxima (FWHM) of the Ag plasmon band (Figure 6(b)). It is interesting to 


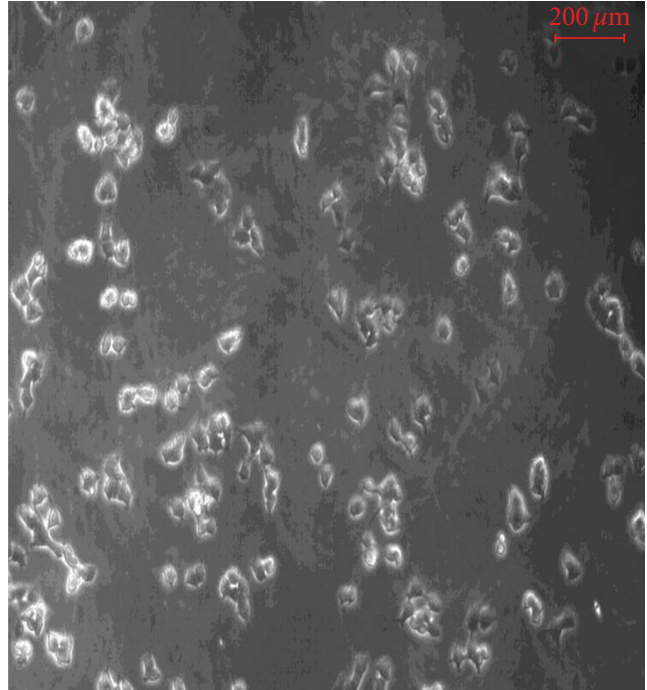

(a)

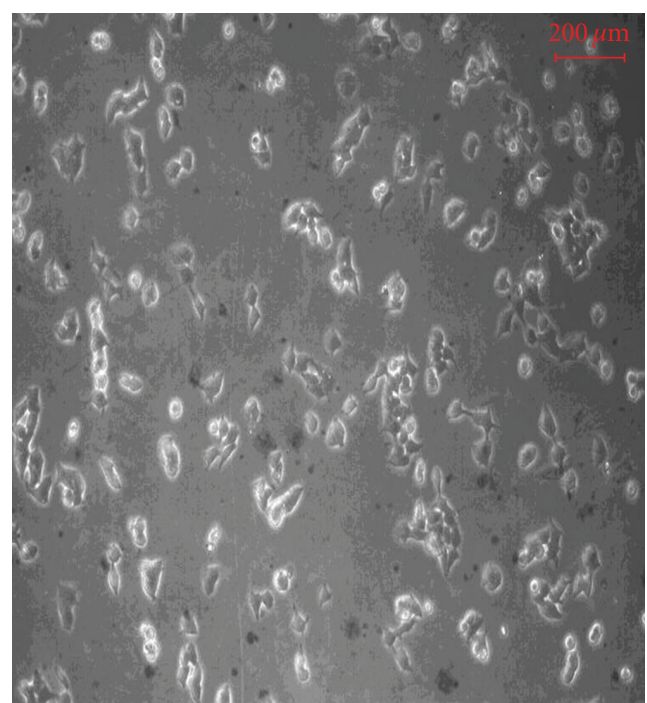

(b)

Figure 8: Optical microscopy images of HEK 293 cells cultured on (a) bare quartz plate and (b) quartz plate coated with (Cs/Ag) 8 after $48 \mathrm{~h}$ exposure.

note that the percentage weight loss of Ag NPs in the hybrid (estimated from the UV-vis spectral intensities) after each cycle, follows the same trend as the percentage survival of bacteria (Figure 6(a)). And also the broadening of peak indicates the possible agglomeration of Ag NPs after each cycle. The decrease in intensity of color of the film further confirms the depletion of Ag particles in the film (inset of Figure 6(b)). The diffusion of Ag NPs into the saline solution may be due to the concentration gradient of $\mathrm{Ag}$ between the film and the solution.

The zone of inhibition carried out for $(\mathrm{Cs} / \mathrm{Ag})_{8}$ hybrid film on stainless steel strip shows interesting results. The aged ( 3 months) film having the same ZOI as that of the just-prepared one is remarkable (Figure 7). This observation accounts for the mechanical stability and retention of antibacterial activity of the $(\mathrm{Cs} / \mathrm{Ag})_{8}$ hybrid film even on aging.

The cytotoxicity assay results for the fabricated $(\mathrm{Cs} / \mathrm{Ag})_{8}$ hybrid film show that the number of live cells after exposure to the film was found to be almost the same as those exposed to control as seen Figure 8 . Thus the attachment and viability of cells vis-a-vis exposure of quartz plate coated (Cs/Ag) 8 indicate that coated film has satisfactory biocompatibility. One can argue that the antibacterial property of the hybrid would be better if one increases the number of bilayers further, but this would be at the cost of cytotoxicity of the material.

\section{Conclusions}

In conclusion, an LBL assembly was fabricated incorporating silver nanoparticles between two layers of positively charged chitosan polymer to obtain eight bilayers of Cs/Ag hybrid through electrostatic interaction. Antibacterial activity was evaluated by both CFU counting and also $\mathrm{OD}_{600}$ test. The hybrid could be effectively cycled for three times. The antimicrobial activity is mainly due to the Ag NPs present in the hybrid. The easily fabricated $(\mathrm{Cs} / \mathrm{Ag})_{8}$ hybrid thin film has good mechanical stability and retains good antibacterial activity against $E$. coli even on aging. This could be a material for coating on some biomedical devices for the prevention of biofilms, which can be attributed to E. coli and may also be used as an antibacterial agent for the purification of water containing E. coli for the limited number of cycles.

\section{Acknowledgments}

The authors thank Professors' Paturu Kondaiah, MRDG, IISc, Bangalore, for in vitro cytotoxicity assay experiments. The authors gratefully acknowledge the internal funding from SSCU department, IISc.

\section{References}

[1] N. Angelova and D. Hunkeler, "Rationalizing the design of polymeric biomaterials," Trends in Biotechnology, vol. 17, no. 10, pp. 409-421, 1999.

[2] J. W. Costerton, P. S. Stewart, and E. P. Greenberg, "Bacterial biofilms: a common cause of persistent infections," Science, vol. 284, no. 5418, pp. 1318-1322, 1999.

[3] L. Hall-Stoodley, J. W. Costerton, and P. Stoodley, "Bacterial biofilms: from the natural environment to infectious diseases," Nature Reviews Microbiology, vol. 2, no. 2, pp. 95-108, 2004.

[4] R. Langer and D. A. Tirrell, "Designing materials for biology and medicine," Nature, vol. 428, no. 6982, pp. 487-492, 2004.

[5] D. Davies, "Understanding biofilm resistance to antibacterial agents," Nature Reviews Drug Discovery, vol. 2, no. 2, pp. 114122, 2003.

[6] L. A. Mermel, L. Mermel, and B. Hudson, "Prevention of intravascular catheter-related infections," Annals of Internal Medicine, vol. 132, no. 5, pp. 391-402, 2000. 
[7] R. M. Klevens, J. R. Edwards, C. L. Richards Jr. et al., "Estimating health care-associated infections and deaths in U.S. Hospitals, 2002," Public Health Reports, vol. 122, no. 2, pp. 160-166, 2007.

[8] J. A. Lichter, K. J. Van Vlietpa, and M. F. Rubner, “Design of antibacterial surfaces and interfaces: polyelectrolyte multilayers as a multifunctional platform," Macromolecules, vol. 42, no. 22, pp. 8573-8586, 2009.

[9] C. A. Fux, J. W. Costerton, P. S. Stewart, and P. Stoodley, "Survival strategies of infectious biofilms," Trends in Microbiology, vol. 13, no. 1, pp. 34-40, 2005.

[10] P. A. Norowski Jr. and J. D. Bumgardner, "Biomaterial and antibiotic strategies for peri-implantitis," Journal of Biomedical Materials Research, vol. 88, no. 2, pp. 530-543, 2009.

[11] P. S. Stewart and J. W. Costerton, "Antibiotic resistance of bacteria in biofilms," The Lancet, vol. 358, no. 9276, pp. 135138, 2001.

[12] J. B. Kaper, J. P. Nataro, and H. L. T. Mobley, "Pathogenic Escherichia coli," Nature Reviews Microbiology, vol. 2, no. 2, pp. 123-140, 2004.

[13] G. O’Toole, H. B. Kaplan, and R. Kolter, "Biofilm formation as microbial development," Annual Review of Microbiology, vol. 54, pp. 49-79, 2000.

[14] R. Van Houdt and C. W. Michiels, "Role of bacterial cell surface structures in Escherichia coli biofilm formation," Research in Microbiology, vol. 156, no. 5-6, pp. 626-633, 2005.

[15] D. J. Stickler, J. B. King, C. Winters, and S. L. Morris, "Blockage of urethral catheters by bacterial biofilms," Journal of Infection, vol. 27, no. 2, pp. 133-135, 1993.

[16] A. Reisner, K. A. Krogfelt, B. M. Klein, E. L. Zechner, and S. Molin, "In vitro biofilm formation of commensal and pathogenic Escherichia coli strains: impact of environmental and genetic factors," Journal of Bacteriology, vol. 188, no. 10, pp. 3572-3581, 2006.

[17] H. Murata, R. R. Koepsel, K. Matyjaszewski, and A. J. Russell, "Permanent, non-leaching antibacterial surfaces-2: how high density cationic surfaces kill bacterial cells," Biomaterials, vol. 28, no. 32, pp. 4870-4879, 2007.

[18] D. Nepal, S. Balasubramanian, A. L. Simonian, and V. A. Davis, "Strong antimicrobial coatings: single-walled carbon nanotubes armored with biopolymers," Nano Letters, vol. 8, no. 7, pp. 1896-1901, 2008.

[19] L. Balan, R. Schneider, and D. J. Lougnot, "A new and convenient route to polyacrylate/silver nanocomposites by lightinduced cross-linking polymerization," Progress in Organic Coatings, vol. 62, no. 3, pp. 351-357, 2008.

[20] C. H. Ho, J. Tobis, C. Sprich, R. Thomann, and J. C. Tiller, "Nanoseparated polymeric networks with multiple antimicrobial properties," Advanced Materials, vol. 16, no. 12, pp. $957-$ 961, 2004

[21] N. P. Desai, S. F. A. Hossainy, and J. A. Hubbell, "Surfaceimmobilized polyethylene oxide for bacterial repellence," Biomaterials, vol. 13, no. 7, pp. 417-420, 1992.

[22] C. Tedjo, K. G. Neoh, E. T. Kang, N. Fang, and V. Chan, "Bacteria-surface interaction in the presence of proteins and surface attached poly(ethylene glycol) methacrylate chains," Journal of Biomedical Materials Research, vol. 82, no. 2, pp. 479-491, 2007.

[23] F. Furno, K. S. Morley, B. Wong et al., "Silver nanoparticles and polymeric medical devices: a new approach to prevention of infection?" Journal of Antimicrobial Chemotherapy, vol. 54, no. 6, pp. 1019-1024, 2004.
[24] S. Ghosh, R. Kaushik, K. Nagalakshmi et al., "Antimicrobial activity of highly stable silver nanoparticles embedded in agaragar matrix as a thin film," Carbohydrate Research, vol. 345, no. 15, pp. 2220-2227, 2010.

[25] P. Jain and T. Pradeep, "Potential of silver nanoparticle-coated polyurethane foam as an antibacterial water filter," Biotechnology and Bioengineering, vol. 90, no. 1, pp. 59-63, 2005.

[26] A. B. G. Lansdown, "Silver 1: its antibacterial properties and mechanism of action," Journal of the Wound Healing, vol. 11, pp. 125-130, 2002.

[27] J. R. Morones, J. L. Elechiguerra, A. Camacho et al., "The bactericidal effect of silver nanoparticles," Nanotechnology, vol. 16, no. 10, pp. 2346-2353, 2005.

[28] P. M. Nguyen, N. S. Zacharia, E. Verploegen, and P. T. Hammond, "Extended release antibacterial layer-by-layer films incorporating linear-dendritic block copolymer micelles," Chemistry of Materials, vol. 19, no. 23, pp. 5524-5530, 2007.

[29] S. Shrivastava, T. Bera, A. Roy, G. Singh, P. Ramachandrarao, and D. Dash, "Characterization of enhanced antibacterial effects of novel silver nanoparticles," Nanotechnology, vol. 18, no. 22, Article ID 225103, 2007.

[30] P. V. AshaRani, G. L. K. Mun, M. P. Hande, and S. Valiyaveettil, "Cytotoxicity and genotoxicity of silver nanoparticles in human cells," ACS Nano, vol. 3, no. 2, article 1471, pp. 279290, 2009.

[31] A. Travan, C. Pelillo, I. Donati et al., "Non-cytotoxic silver nanoparticle-polysaccharide nanocomposites with antimicrobial activity," Biomacromolecules, vol. 10, no. 6, pp. 1429-1435, 2009.

[32] C. Baker, A. Pradhan, L. Pakstis, D. J. Pochan, and S. I. Shah, "Synthesis and antibacterial properties of silver nanoparticles," Journal of Nanoscience and Nanotechnology, vol. 5, no. 2, pp. 244-249, 2005.

[33] F. Caruso, C. Schüler, and D. G. Kurth, "Core-shell particles and hollow shells containing metallo-supramolecular components," Chemistry of Materials, vol. 11, no. 11, pp. 3394-3399, 1999.

[34] S. A. Jones, P. G. Bowler, M. Walker, and D. Parsons, "Controlling wound bioburden with a novel silver-containing Hydrofiber dressing," Wound Repair and Regeneration, vol. 12, no. 3, pp. 288-294, 2004.

[35] L. Kvítek, A. Panáček, J. Soukupová et al., "Effect of surfactants and polymers on stability and antibacterial activity of silver nanoparticles (NPs)," Journal of Physical Chemistry C, vol. 112, no. 15, pp. 5825-5834, 2008.

[36] D. R. Monteiro, L. F. Gorup, A. S. Takamiya, A. C. RuvolloFilho, E. R. D. Camargo, and D. B. Barbosa, "The growing importance of materials that prevent microbial adhesion: antimicrobial effect of medical devices containing silver," International Journal of Antimicrobial Agents, vol. 34, no. 2, pp. 103-110, 2009.

[37] Q. Li, S. Mahendra, D. Y. Lyon et al., "Antimicrobial nanomaterials for water disinfection and microbial control: potential applications and implications," Water Research, vol. 42, no. 18, pp. 4591-4602, 2008.

[38] U. Manna, J. Dhar, R. Nayak, and S. Patil, "Multilayer singlecomponent thin films and microcapsules via covalent bonded layer-by-layer self-assembly," Chemical Communications, vol. 46, no. 13, pp. 2250-2252, 2010.

[39] D. Radziuk, D. G. Shchukin, A. Skirtach, H. Möhwald, and G. Sükhorukov, "Synthesis of silver nanoparticles for remote opening of polyelectrolyte microcapsules," Langmuir, vol. 23, no. 8, pp. 4612-4617, 2007. 
[40] E. Donath, G. B. Sukhorukov, F. Caruso, S. A. Davis, and H. Möhwald, "Novel hollow polymer shells by colloid-templated assembly of polyelectrolytes," Angewandte Chemie-International Edition, vol. 37, no. 16, pp. 2202-2205, 1998.

[41] U. Manna and S. Patil, "Encapsulation of uncharged waterinsoluble organic substance in polymeric membrane capsules via layer-by-layer approach," Journal of Physical Chemistry B, vol. 112, no. 42, pp. 13258-13262, 2008.

[42] I. Pastoriza-Santos, B. Schöler, and F. Caruso, "Core-shell colloids and hollow polyelectrolyte capsules based on diazoresins," Advanced Funtional Materials, vol. 11, no. 2, pp. 122-128, 2001.

[43] C. Schüler and F. Caruso, "Decomposable hollow biopolymerbased capsules," Biomacromolecules, vol. 2, no. 3, pp. 921-926, 2001.

[44] M. T. Crisp and N. A. Kotov, "Preparation of nanoparticle coatings on surfaces of complex geometry," Nano Letters, vol. 3, no. 2, pp. 173-177, 2003.

[45] T. J. Halthur, P. M. Claesson, and U. M. Elofsson, "Stability of polypeptide multilayers as studied by in situ ellipsometry: effects of drying and post-buildup changes in temperature and $\mathrm{pH}$," Journal of the American Chemical Society, vol. 126, no. 51, pp. 17009-17015, 2004.

[46] R. A. McAloney, M. Sinyor, V. Dudnik, and M. Cynthia Goh, "Atomic force microscopy studies of salt effects on polyelectrolyte multilayer film morphology," Langmuir, vol. 17, no. 21, pp. 6655-6663, 2001.

[47] S. S. Shiratori and M. F. Rubner, "pH-dependent thickness behavior of sequentially adsorbed layers of weak polyelectrolytes," Macromolecules, vol. 33, no. 11, pp. 4213-4219, 2000.

[48] J. Fu, A. Ji, D. Fan, and J. Shen, "Construction of antibacterial multilayer films containing nanosilver via layer-by-layer assembly of heparin and chitosan-silver ions complex," Journal of Biomedical Materials Research, vol. 79, no. 3, pp. 665-674, 2006.

[49] J. W. Rhim, S. I. Hong, H. M. Park, and P. K. W. Ng, "Preparation and characterization of chitosan-based nanocomposite films with antimicrobial activity," Journal of Agricultural and Food Chemistry, vol. 54, no. 16, pp. 5814-5822, 2006.

[50] V. Thomas, M. M. Yallapu, B. Sreedhar, and S. K. Bajpai, "Fabrication, characterization of chitosan/nanosilver film and its potential antibacterial application," Journal of Biomaterials Science, Polymer Edition, vol. 20, no. 14, pp. 2129-2144, 2009.

[51] K. S.V. Krishna Rao, P. Ramasubba Reddy, Y. I. Lee, and C. Kim, "Synthesis and characterization of chitosan-PEG-Ag nanocomposites for antimicrobial application," Carbohydrate Polymers, vol. 87, no. 1, pp. 920-925, 2012.

[52] W. Yuan, J. Fu, K. Su, and J. Ji, "Self-assembled chitosan/ heparin multilayer film as a novel template for in situ synthesis of silver nanoparticles," Colloids and Surfaces B, vol. 76, no. 2, pp. 549-555, 2010.

[53] D. G. Yu, W. C. Lin, and M. C. Yang, "Surface modification of poly(L-lactic acid) membrane via layer-by-layer assembly of silver nanoparticle-embedded polyelectrolyte multilayer," Bioconjugate Chemistry, vol. 18, no. 5, pp. 1521-1529, 2007.

[54] D. Wei, W. Sun, W. Qian, Y. Ye, and X. Ma, "The synthesis of chitosan-based silver nanoparticles and their antibacterial activity," Carbohydrate Research, vol. 344, no. 17, pp. 23752382, 2009.

[55] V. Sambhy, M. M. MacBride, B. R. Peterson, and A. Sen, "Silver bromide nanoparticle/polymer composites: dual action tunable antimicrobial materials," Journal of the American Chemical Society, vol. 128, no. 30, pp. 9798-9808, 2006.
[56] R. O. Darouiche, "Device-associated infections: a macroproblem that starts with microadherence," Clinical Infectious Diseases, vol. 33, no. 9, pp. 1567-1572, 2001.

[57] WHO/UNICEF, "Meeting the MDG Drinking Water and Sanitation Target: A Mid-Term Assessment of Progress," WHO, Geneva, Switzerland, 2004.

[58] G. Appierot, A. Lipovsky, R. Dror et al., "Enhanced antibacterial actiwity of nanocrystalline $\mathrm{ZnO}$ due to increased ROSmediated cell injury," Advanced Functional Materials, vol. 19, no. 6, pp. 842-852, 2009.

[59] Y. Yang, L. Xiong, J. Shi, and M. Nogami, "Aligned silver nanorod arrays for surface-enhanced Raman scattering," Nanotechnology, vol. 17, no. 10, pp. 2670-2674, 2006.

[60] M. Minier, M. Salmain, N. Yacoubi et al., "Covalent immobilization of lysozyme on stainless steel. Interface spectroscopic characterization and measurement of enzymatic activity," Langmuir, vol. 21, no. 13, pp. 5957-5965, 2005.

[61] I. R. Freshney, Culture of Animal Cells: A Manual of Basic Technique, Wiley-Liss, New York, NY, USA, 3rd edition, 1994.

[62] A. Dror-Ehre, A. Adin, G. Markovich, and H. Mamane, "Control of biofilm formation in water using molecularly capped silver nanoparticles," Water Research, vol. 44, no. 8, pp. 26012609, 2010.

[63] P. Gopinath, S. K. Gogoi, A. Chattopadhyay, and S. S. Ghosh, "Implications of silver nanoparticle induced cell apoptosis for in vitro gene therapy," Nanotechnology, vol. 19, no. 7, pp. 075104-075113, 2008.

[64] M. Rinaudo, "Chitin and chitosan: properties and applications," Progress in Polymer Science (Oxford), vol. 31, no. 7, pp. 603-632, 2006.

[65] S. Ladet, L. David, and A. Domard, "Multi-membrane hydrogels," Nature, vol. 452, no. 7183, pp. 76-79, 2008.

[66] Y. Y. Chen, C. C. Wu, J. L. Hsu, H. L. Peng, H. Y. Chang, and T. R. Yew, "Surface rigidity change of Escherichia coli after filamentous bacteriophage infection," Langmuir, vol. 25, no. 8, pp. 4607-4614, 2009.

[67] S. K. Gogoi, P. Gopinath, A. Paul, A. Ramesh, S. S. Ghosh, and A. Chattopadhyay, "Green fluorescent protein-expressing Escherichia coli as a model system for investigating the antimicrobial activities of silver nanoparticles," Langmuir, vol. 22, no. 22, pp. 9322-9328, 2006.

[68] W. R. Li, X. B. Xie, Q. S. Shi, H. Y. Zeng, Y. S. Ou-Yang, and Y. B. Chen, "Antibacterial activity and mechanism of silver nanoparticles on Escherichia coli," Applied Microbiology and Biotechnology, vol. 85, no. 4, pp. 1115-1122, 2010.

[69] I. A. Shurygina, B. G. Sukhov, T. V. Fadeeva et al., "Bactericidal action of $\operatorname{Ag}(0)$-antithrombotic sulfated arabinogalactan nanocomposite: coevolution of initial nanocomposite and living microbial cell to a novel nonliving nanocomposite," Nanomedicine, vol. 7, no. 6, pp. 827-833, 2011.

[70] A. Atabek and T. A. Camesano, "Atomic force microscopy study of the effect of lipopolysaccharides and extracellular polymers on adhesion of Pseudomonas aeruginosa," Journal of Bacteriology, vol. 189, no. 23, pp. 8503-8509, 2007.

[71] V. Alt, T. Bechert, P. Steinrücke et al., "An in vitro assessment of the antibacterial properties and cytotoxicity of nanoparticulate silver bone cement," Biomaterials, vol. 25, no. 18, pp. 4383-4391, 2004.

[72] M. R. Salton, "Structure and function of bacterial cell membranes," Annual Review of Microbiology, vol. 21, pp. 417-442, 1967. 


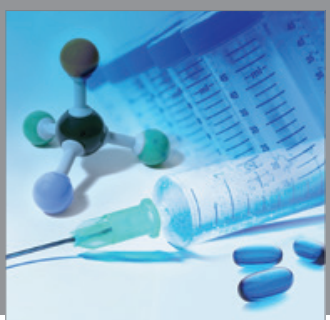

International Journal of

Medicinal Chemistry

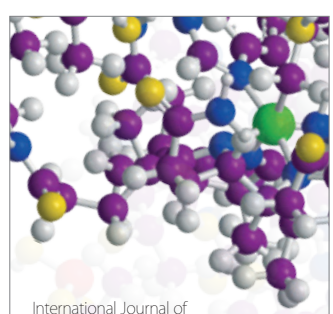

Carbohydrate Chemistry

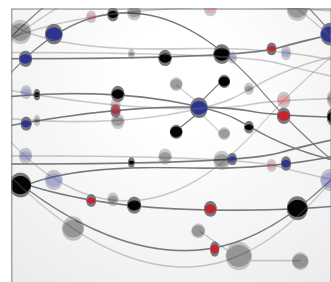

The Scientific World Journal
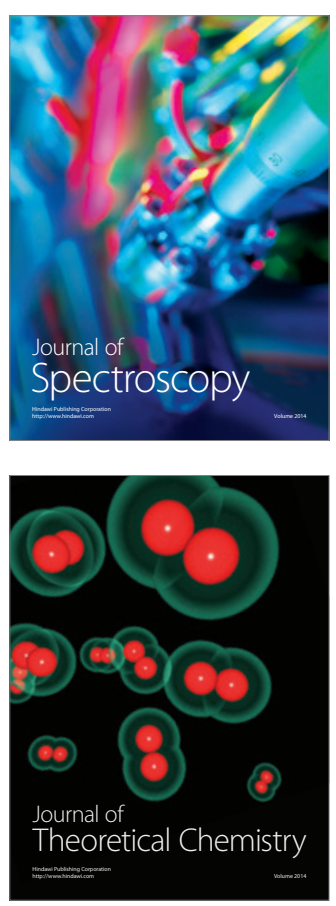
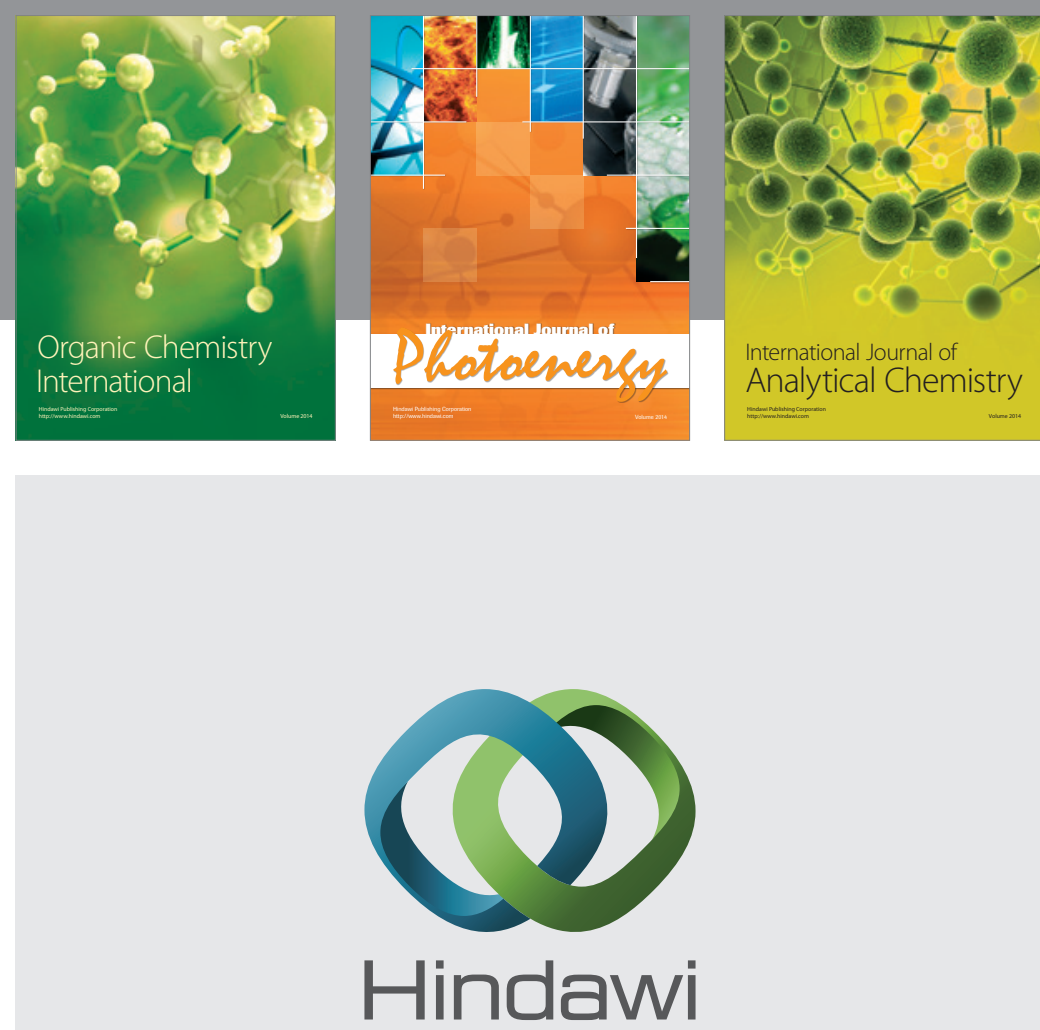

Submit your manuscripts at

http://www.hindawi.com
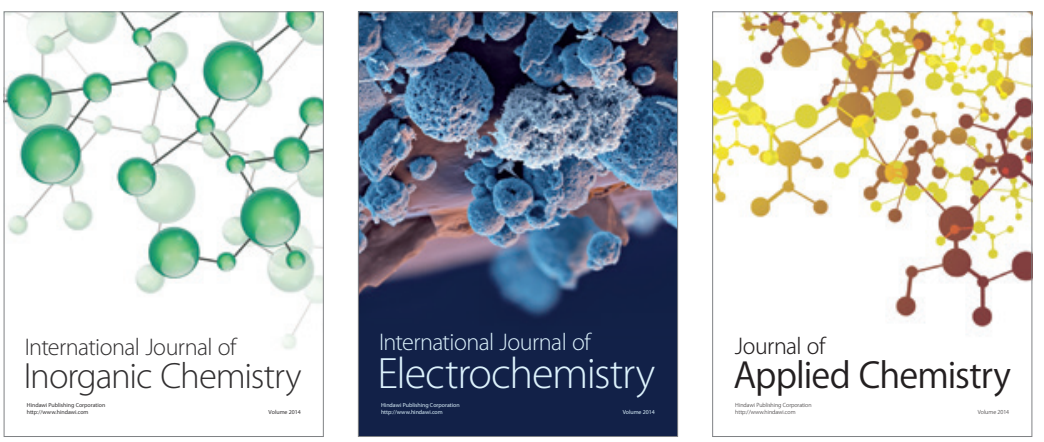

Journal of

Applied Chemistry
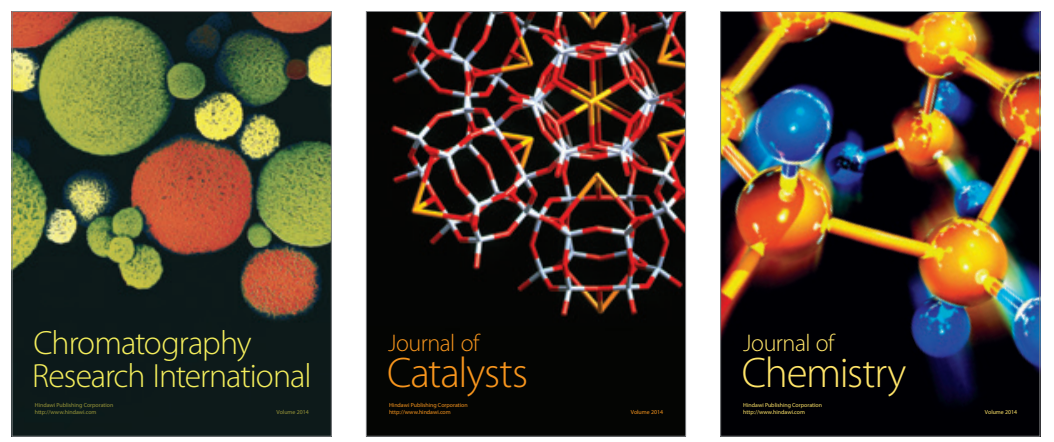
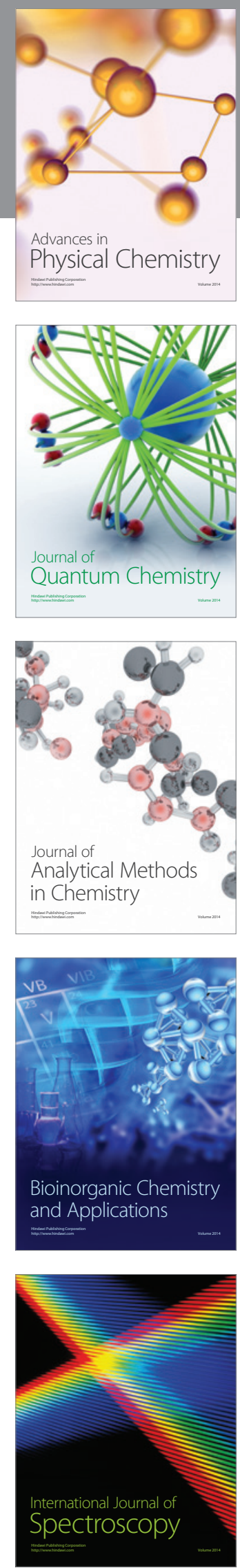